\title{
Personnel: Staffing the Asylums and Serving the Colours
}

\section{INTRODUCTION}

A parliamentary select committee in 1911 discussed a London County Council (LCC) survey of its asylum staff. It showed that they did not become insane any more than members of the general public despite their proximity to insane people day after day. This finding surprised the committee. It challenged their assumptions about the transmissibility of insanity. The LCC explained that their staff were "specially selected for their mental and physical fitness", and were therefore resilient, but the Medico-Psychological Association (MPA) challenged the ease of appointing suitable staff: asylums needed more staff who were "in sympathy with the insane" and who did not behave like "warder to convict". 2

In 1914, the LCC employed 3500 staff across its ten asylums. ${ }^{3}$ They were appointed with the aim of supporting patients who required medical, psychological and social forms of treatment to allow them to have the best possible quality of life, either long-term in the asylums, or by recovering and returning to the community. In addition to doctors and male ward attendants on the men's wards and female nurses mainly on the women's wards, there were shoemakers, tinsmiths, tailors, upholsterers and other artisans who worked alongside clergy, kitchen and laundry workers, and other who maintained buildings, farm, gardens and cemetery. ${ }^{4}$ Sometimes whole families worked at an asylum, such as the Mingays

(C) The Author(s) 2021

C. Hilton, Civilian Lunatic Asylums During the First World War, Mental Health in Historical Perspective, https://doi.org/10.1007/978-3-030-54871-1_4 
at Colney Hatch, who fulfilled roles of porter, organist, ward attendant and work-mistress responsible for finding and supervising daily activities for women patients. ${ }^{5}$ This chapter seeks to explore the experiences of the staff, the challenges facing them, and how they coped. Many staff lived on the asylum estate. Some had their rooms adjacent to wards, others lived in nurses' homes, and others in staff cottages with their families. All were subject to strict disciplinary rules, in a similar way to their patients. Some had formal professional qualifications, others did not. The majority were low in the ranks of the hierarchical system of asylum management which threaded through from government, via the Board of Control ("the Board") and into the asylums. Staff life changed during the war, associated with many male staff serving the Colours, new gender roles, and the hardships of civilian life which were particularly intense in the asylums.

\section{The Staff on the Asylum Front Line}

In 1914, Viscount Wolmer MP asked Prime Minister Herbert Asquith whether he was aware of unrest among asylum staff in various parts of the country. Asquith informed the House of Commons that "there is no widespread unrest, though some dissatisfaction does undoubtedly exist." 6 This did not bode well for future stressful circumstances. The Board realised that wartime changes would cause staff anxiety and inconvenience, but they were sure that these "would be cheerfully borne" and not detrimental to patients. ${ }^{7}$ In 1915, psychiatrist Sir James Crichton Brown said about wartime asylum staff:

They have been left short-handed, they have had double duty thrown upon them, they have had to work overtime, they have had a most anxious and wearing experience,...their wages have been practically reduced, for the purchasing power of a sovereign is not now what it was twelve months ago. ${ }^{8}$

Some staff responded to the pressures of work and deprivation in unprofessional ways. The minutes of Colney Hatch asylum's lay management, or "visiting", committee (VC) recount how Nurse Hammond found Nurse Laycock in a ward storeroom drinking the patients' milk and Nurse Davies holding a cup of milk under her apron. Nurse Hammond reported her colleagues to a more senior nurse. Later that day, someone ransacked 
Nurse Hammond's bedroom, and she was assaulted on a dark corridor, covered with a wet sheet then ducked in a bath of cold water. The alleged milk-thieves were summoned to the medical superintendent who was put in the invidious position of having to get to the root of the dispute. Numerous other allegations emerged including food being misappropriated and patients being dragged by the hair and hit by senior staff. Many of the backlog of accounts were inconsistent or contradictory, suggesting staff covering up or blaming each other in the context of a malfunctioning ward team. All three nurses resigned. ${ }^{9}$

Staff were expected to conform to strict regimes of discipline and control, imposed on them in both employment and personal spheres, a pattern common in "total institutions". 10 There were many ways in which VCs could detect infringements of rules, some simpler ones being to install "time clocks" which required staff to "peg in" their key to monitor punctuality, or using electric "tell-tale clocks" to make sure they did not fall asleep on night duty. ${ }^{11}$ At a minimum, disobedience or a lapse of behaviour meant that the accused appeared before the $\mathrm{VC}$ or medical superintendent to account for their deeds. Internal inquiries gave staff no right of representation or appeal or other safeguards, risking unjust penalties. Being admonished by the medical superintendent or the VC chairman, and having their misdemeanour entered into a register of staff offences was humiliating, ${ }^{12}$ but some misdemeanours were associated with severe penalties, such as being demoted, instantly dismissed, or prosecuted. ${ }^{13}$ In 1916, Hanwell VC dismissed an attendant of longstanding "For taking patients meat neglecting to give to the Patients part of the meat issued". ${ }^{14}$ The hand-written, altered entry in the harshly named "fine book", was compatible with reducing the allegation from criminal, which required a police investigation, to a misdemeanour which allowed dismissal. The latter was more convenient for the VC, and it was kinder to staff who, although losing their job and forfeiting their superannuation contributions, did not acquire a criminal record. ${ }^{15}$ Dismissal removed the offender, and their threat to the asylum's reputation, but provided little stimulus for the leadership to learn from events, or consider systemic problems within their asylum, to prevent further transgressions. Dedicated staff were sometimes dismissed for a genuine error of judgement, although occasionally wartime constraints militated in their favour, such as for an attendant at Claybury of 14 years standing with a previous good work record, under whose watch a patient committed suicide: he 
remained in post because the medical superintendent had "no better man to replace him with."16

Entries in Hanwell's fine book were few and far between compared to the number of staff employed, suggesting that most staff behaved according to expectations of the leadership. However, the data need to be interpreted cautiously as the entries indicate the staff caught and their misdemeanours judged appropriate for recording in the book, rather than the total number of subversive or aberrant staff whose behaviours passed unnoticed. Occasionally, alongside many reprimands for breaking rules, such as giving ward keys to a patient, or playing draughts or ball games with other staff while on duty, praise was put on permanent record: Joseph Taylor was "Commended for action taken whereby a patient's life was saved". 17 This type of entry was unusual, as staff were assumed to be dedicated and kind, and they received little, if any, praise. Bedford Pierce, medical superintendent at the York Retreat, criticised his colleagues who did not encourage their VCs to show appreciation to their staff whose work was arduous and pay "miserably poor". 18

Regarding staff personal lives, the VC kept a close eye on comings and goings and regulated their staff in many ways: even matron had to seek permission to have a guest staying in her quarters. ${ }^{19}$ Some asylums stipulated times for staff to go to bed and to get up. ${ }^{20}$ Resident day staff were generally allowed out of the asylum between 8 and 10 p.m., ${ }^{21}$ after the night staff came on duty, although that freedom was regulated almost as stringently as parole for patients. Similar to patients, leave could be given as a reward, or withdrawn as punishment, such as happened to two nurses caught stealing fruit at Napsbury. ${ }^{22}$ Staff were also disciplined if they mis-used their freedom, such as returning later than their night-pass permitted. ${ }^{23}$ Eliza Maidman, a laundry-maid at Colney Hatch for over 25 years who lived-in, ${ }^{24}$ had a pass to leave the asylum for an evening. It expired at 10 p.m., but she arrived back at 5.35 a.m. the following morning. Summoned to the VC to account for her behaviour, she stated that she was delayed by a Zeppelin raid. With heavy raids just north of London, the VC did not question her further. ${ }^{25}$ Her determination to return in time to start work the following morning was admirable. She was loyal to her asylum-her home, workplace and communityand appeared accepting of its rules. It is disconcerting that, just as praise for Joseph Taylor was found in the fine book, an investigation into suspected misdemeanours was the route into discovering a staff member's commitment. 
Sometimes VCs showed compassion to staff in difficulty, such as giving paid leave to a member of staff to care for her sick husband who was also an employee of the asylum. ${ }^{26}$ At other times, compassion was wanting. When Nurse Gertrude Stephens, a single woman, was pregnant, the rules gave her no choice but to resign from her job. Her child was stillborn. Since she was no longer employed by the asylum, she asked, as she was entitled to do, for her superannuation payments to be returned to her. ${ }^{27}$ The VC refused, on the grounds that her services were terminated "by reason of her own misconduct." She had no job, no child and no money to tide her over. ${ }^{28} \mathrm{~A}$ comparable sort of callousness was shown towards a 19-year-old woman who had received an offer of work at Colney Hatch. Mid-war, she travelled from Ireland to take up her post, but probably due to head lice, she was rejected, and sent away penniless. She sought shelter in a convent. Since she was not the first to reach the nuns in similar circumstances, they relayed her story to a magistrate. He wrote to the medical superintendent saying that she had been "thrown to the wolves by one of [her] own sex". 29

Other asylum rules concerned staff who wanted to marry. Female staff were expected to leave their job on marriage. However, with difficulty recruiting staff and soaring hasty marriage rates, particularly of soldiers tying the knot with their sweethearts before departing to the war front or while on leave, ${ }^{30}$ compromises were needed. In this case, married nurses could return to asylum work, but only to temporary positions, ${ }^{31}$ giving them little job security. ${ }^{32}$ Male staff who wanted to marry also faced challenges, associated with limited married accommodation in the asylum grounds. ${ }^{33}$ They too had to seek consent from the asylum leadership, with permission usually only being granted to those who had given 5 years' service, seniority giving priority for coveted accommodation. Similar marriage rules applied to doctors: without permission from the medical superintendent, doctors who married could be dismissed and forfeit their superannuation payments, even if the marriage took place while they were on military service. ${ }^{34}$ Strict rules, about where staff lived, on- or off-site, began to change, in some places, before the war. ${ }^{35}$ This was partly due to insufficient and unsuitable nurses' homes, such as one with only 2 baths for 79 nurses which gave nurses no option but to bathe on the wards. ${ }^{36}$ More asylums permitted living-out during the war, influenced by the demands of temporary attendants who were concerned about the well-being of their own families in the event of an air raid. ${ }^{37}$ 
Regarding the work undertaken on the wards, the select committee in 1911 described it as "irksome", and Neil Brimblecombe, in his study of asylum nursing until 1910, described it as hard and often unpleasant. ${ }^{38}$ The type of work, often with an 80-hour working week on a two-shift per day rota, combined with a punitive style of asylum leadership and strict discipline, probably contributed to the high turnover of asylum staff, in some places over 75 per cent annually. This resulted in an inexperienced workforce, potentially detrimental to patients, and with further recruitment being time consuming for the leadership. ${ }^{39}$ The select committee recommended reducing the hours of work, ${ }^{40}$ but the Board disagreed, arguing that more changes in staff through the day would be disruptive to patients. ${ }^{41}$ The Board's stance altered, however, and by 1914 it considered an 80 -hour week too onerous. ${ }^{42}$ Around the same time, the LCC tried to implement a 66-hour week for ward staff. This was close to the 60-hour week worked by asylum staff in jobs off the wards, but still more than the typical working week of 50 hours in most industrial and agricultural labour sectors. ${ }^{43}$ The LCC began to envisage benefits accruing from fewer hours, such as staff being less exhausted and therefore able to work more therapeutically with the patients, a change which might also encourage staff retention and recruitment. More staff, however, would be expensive.

Alongside challenges from the type and hours of ward work and asylum culture and accommodation, terms of employment were problematic and required improvement to secure the best possible staff. ${ }^{44}$ The staffing situation was similarly "critical" in Scottish asylums. There, recommendations were made to relax over-rigid discipline and "systematic petty tyranny", and to improve accommodation, conditions of service, pay, and pension rights to match the higher standards achieved by other public bodies, notably the Prison Service. ${ }^{45}$ However, the LCC was complacent when it came to improving these employment conditions, as were some VCs who appeared out of touch with their staff. ${ }^{46}$ Harsh discipline and hierarchical management were unlikely to foster a trusting relationship between seniors and juniors ${ }^{47}$ and the punitive culture aroused apprehension and "a general feeling of insecurity" among staff. ${ }^{48}$ These factors probably also encouraged dishonesty and concealment, with inconsistent and contradictory reporting of incidents, such as the events around the milk-thieves. As the war edged on, little was done to remedy staff working conditions. Staff suffered high rates of sickness and absence, and many resigned. ${ }^{49}$ They did not become insane, but constituted a fragile body 
of workers. One temporary wartime attendant summarised his experience: "I was only there for a month - I could not stand it any longer." 50

\section{Hierarchies}

Most staff were low in the ranks of the pervasive, almost feudal asylum hierarchy. The pecking order placed the medical superintendent at the top. $\mathrm{He}$ (there were no women in this role in the public asylums) had often climbed the medical career ladder in the same institution. Under him came the asylum "officers" including other doctors (hence known as "medical officers"), and senior staff in all disciplines, including matron, chaplain, steward (responsible for managing supplies, stores, staffing and day-to-day operation of the asylum) and farm bailiff. Below them came the main body of staff, then the probationers and finally the patients. Salaries and size of accommodation reflected the hierarchy. The medical superintendent at Colney Hatch received an annual salary of over $£ 1000$. ${ }^{51}$ Required to live on site by the Lunacy Act, ${ }^{52}$ he usually had a substantial house demonstrating his status within the asylum (Fig. 4.1). Its grandeur partly compensated for the freedom given to his medical and surgical colleagues of similar seniority who could choose their homes in more fashionable locations.

Junior doctors fared better than senior nurses, indicative of the overall medical hierarchy. A temporary assistant medical officer earnt about $£ 300$ a year, while matron's starting salary was around $£ 100$ plus emoluments. ${ }^{53}$ The head attendant, who might have a cottage in the grounds if married, received about $£ 80$ plus $£ 50$ emoluments plus overtime. He might also be eligible for bonuses, such as the "war bonus" to help cover steep price rises. ${ }^{54}$ The pay-roll at Colney Hatch showed that Miss Mingay, the work-mistress, received $£ 46$ plus $£ 47$ emoluments, and female probationer nurses earnt $£ 20$ plus board, lodging, laundry and uniform. ${ }^{55}$ Although difficult to compare directly, for most staff, pay combined with emoluments was roughly equivalent to salaries of agricultural or factory labourers or domestic servants, ${ }^{56}$ ranking their "worth" as employees among the lower tiers of the working class.

During the war, the VCs accorded the most junior ward staff, alongside temporary staff of almost all disciplines, a status only minimally higher than that of patients. ${ }^{57}$ Also like the patients, junior and temporary staff were expected to be uncritical of asylum practices, or "to obey the 'God 


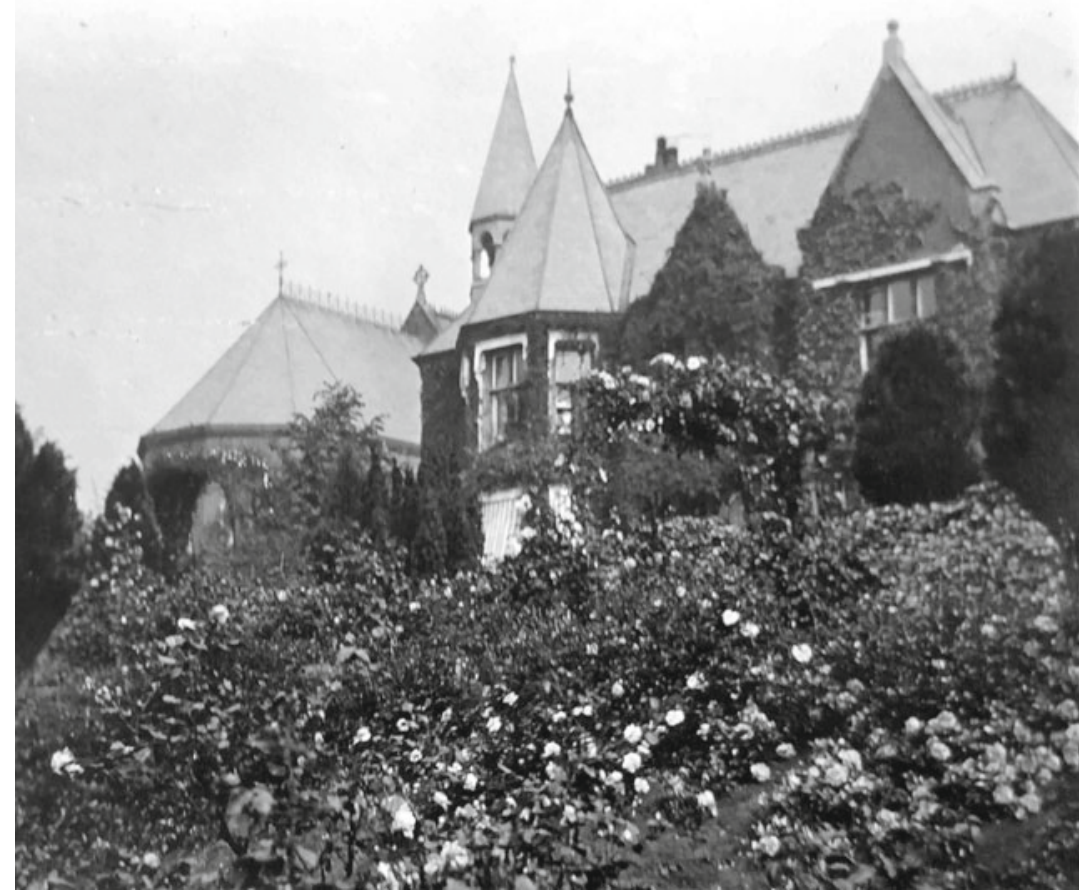

Fig. 4.1 The medical superintendent's house at Claybury, photographed from the rose garden, before 1917. The chapel is behind the house, to the left (Armstrong-Jones collection, Royal College of Psychiatrists' Archives)

of things as they are,' not of 'things as they should be", in the words of Montagu Lomax, whose book about his wartime asylum work subsequently triggered the Cobb Inquiry into asylum practices. ${ }^{58}$ With the risk of being dismissed for criticising the authorities, Lomax was aware that he had to take a difficult ethical decision: either to complain and risk being dismissed, or to continue to observe while part of the asylum system for long enough to write about his experiences at a later date. ${ }^{59}$

For ward staff, a practical demonstration of their place in the hierarchy was provided by the quality of their uniforms which could be little better than the clothing supplied to patients: when one attendant left Colney Hatch wearing his second-hand uniform, the VC was not concerned as it 
"would only have been fit to put in the rag bag". ${ }^{60}$ Ward staff, however, regarding themselves as higher in the hierarchy than the patients, took it upon themselves to demonstrate their superiority and power over those in their charge. One way to do this was for ward staff to carry huge bunches of keys, sometimes 30 or more; the Board doubted that so many different locks were "really necessary" for security. ${ }^{61}$ Monitoring ward staff, such as by them pegging in or recording their activities in registers, did not give oversight of the quality of their practice: behind locked doors on wards, staff were often unsupervised with their patients. One former patient observed that attendants had "almost unlimited power in dealing with patients unbeknown to the doctor" 62 and another commented: "The Visiting Committee are only a bit of eyewash; the attendants govern the asylum". ${ }^{63}$ It is conceivable that ward staff, treated with little respect by their seniors in an authoritarian culture which did little to encourage kindness, would model their behaviours towards patients on the harsh and punitive ways in which they were treated. ${ }^{64}$ The behaviour of seniors as models was particularly important for staff who had little formal training for the roles and responsibilities which they were expected to undertake. This would not foster practices which matched ideals of humane and attentive asylum care as promoted by forward-thinking psychiatrists and a wishful-thinking Board. ${ }^{65}$

\section{Gender, Status and Staff Education}

The Lunacy Act ruled on gender segregation in asylums. It forbade any "male person" from having "personal custody" of any female patient, ${ }^{66}$ so attendants provided day-to-day care for male patients, and nurses for female patients. Of necessity, since most doctors were male, they were permitted to work with male and female patients, chaperoned on their rounds where appropriate. ${ }^{67}$ Culture also influenced practices and debates on gender and ward staffing. In Scotland, but not in England or Wales, asylums encouraged female nurses to care for male psychiatric patients. One Scottish medical superintendent, George Robertson, later professor of psychiatry in Edinburgh, spoke about women's "mothering instincts, and natural gifts for the nursing and care of male patients", as in general hospitals. Women, he said, could manage disturbed men, because they used persuasion rather than a "show of force": 
Excited patients who are ready to fight any man who comes near them will often do anything they are told by a nurse, and they will become calm if they receive a word of sympathy from her....it is absurd to assume that all feelings of chivalry and honour die in a man because he suffers from some derangement of the mind. 68

Relatives also liked women nursing their menfolk as they feared less violence from them. ${ }^{69}$ South of the border, many VCs considered it improper for women to nurse men and preferred male staff who could use their physical prowess to control patients if necessary. This contributed to propagating unwholesome images of asylums and mental disorders as synonymous with violence.

Asylum nursing in England not only differed from that in Scotland but it also contrasted with the model of "general" nursing for physical disorders and injury. General nursing was a respectable vocation for middle class women, developed by Florence Nightingale, the pioneering leader of modern nursing, and professionalized through education and organisation. Practices of asylum nurses had some commonalities with the Nightingale tradition, whereas attendants tended to adopt their model of care from military orderlies. Nevertheless, the low status of asylum ward staff made them uneasy that their better trained and middle class general nursing colleagues might take over some of their roles and responsibilities. $^{70}$

Military demands dramatically reduced the availability of attendants, ${ }^{71}$ necessitating further consideration of nurses filling their posts. ${ }^{72}$ There were practical and moral considerations. In many asylums there were barely sufficient nurses to staff the female wards, let alone the rest of the asylum. Much discussion focussed on whether nurses should bathe insane men or if work with disturbed men was suitable for younger nurses, and what might be done in asylums where ward staff had their bedrooms on or adjoining the wards, an arrangement which aimed to facilitate them responding to an emergency at night. ${ }^{73}$ Taking a lead from general nursing where women nursed physically incapacitated men, some VCs introduced nurses onto their male infirmary wards where the patients were also physically unwell, and onto wards "occupied mainly by senile cases". ${ }^{74}$ Some asylums encouraged nurses to volunteer to work on the male wards, elsewhere they were dismissed if they refused orders do so. ${ }^{75}$

Until the war, domestic service was the likely previous employment experience of women taking up posts in asylums. ${ }^{76}$ During the war, 
with the wide range of employment opportunities available to women, some entered the asylum service having worked in day nurseries, hospitals, shops, munitions and other industries. ${ }^{77}$ This gave them more skills and experiences of industrial-scale organisations and employment rights, which they used to further their own careers. When, for example, VCs told nurses that they could not be spared to undertake nursing of soldiers because of asylum staffing needs, they left anyway. ${ }^{78}$ In the LCC's opinion "something should be done speedily" to make it worthwhile for women to remain on the asylum staff, rather than to move into jobs regarded as more glamorous or lucrative. ${ }^{79}$ Gender had other implications for the asylums during the war years, as although more women than men were employed in lower ranks of asylum work, they were few and far between in the higher tiers. A few were appointed to roles which required specific training or expertise, such as doctors or pharmacists, ${ }^{80}$ but more affluent women, who traditionally took on voluntary roles, remained under-represented: only six of 25 members of the LCC asylum committee were female. ${ }^{81}$

Other forces which shaped asylum practices included the trade unions. They favoured gender segregation in asylums as they feared that employing women in male roles might jeopardise jobs for men, and that since women received lower pay, VCs might maintain their wartime female workforce indefinitely as a cheaper option. ${ }^{82}$ Women usually earnt about 20 per cent less than men for the same job, and only men were entitled to long-term service bonuses after five and ten years. The salary difference created unrest among women staff. Rarely, as in the case of experienced female agricultural workers on the asylum farms, they received the same wages as men, but capped so as not to exceed them. ${ }^{83}$ The LCC ignored trade unions' war time requests about equal pay and stalled negotiations until after the war, on the grounds that such decisions warranted a government committee to consider the principles underlying it. ${ }^{84}$ The LCC also debated female labour versus machines, such as for milking cows on the asylum farm, a task previously undertaken by men. ${ }^{85}$ No-one appeared to advocate for fair-play for the cheapest option: patient labour. Patients replaced female staff on Claybury's farm when seven out of the eight staff left, dissatisfied with their wages. The patients who took over were allowed "extra cheese and jam for lunch and oatmeal water during the afternoon" but received no salary. ${ }^{86}$

Regarding education and training, a better trained workforce was assumed to be more productive and effective. ${ }^{87}$ The MPA accepted that 
ward staff needed training, although Vicky Long argued that this was associated with a degree of self-interest, psychiatrists recognising that their own image was inexorably bound up with that of other staff. ${ }^{88}$ Even if psychiatrists' image was a major concern of the MPA, it is admirable that it established a mental nursing syllabus, examinations and the "Certificate of Proficiency in Nursing the Insane", in the context of the general nursing profession keeping itself at arm's length from the asylums and there being no comparable established system of asylum ward staff leadership to develop the training themselves. ${ }^{89}$ Introducing formal training to a workforce which had had little opportunity for study after leaving school, typically at age 12 years, ${ }^{90}$ was an achievement. It was also a challenge for some asylum doctors who were expected to train their staff, having had little formal psychiatric training themselves. They might perceive that giving staff a recognised specialist qualification, when they had none, was a threat to their own status. ${ }^{91}$

The MPA's Handbook for Attendants on the Insane, was updated regularly and reached its sixth edition in 1911.92 Asylums purchased the Handbook by the dozen. ${ }^{93}$ The doctors gave lectures, which in some asylums received sufficient priority to be continued during the war. ${ }^{94}$ The subject matter of the course was mostly theoretical, a watered-down version of the medical curriculum, lacking creativity to take into account the different practical tasks undertaken by doctors and ward staff. Not everyone regarded formal training as important: one doctor cited a staff representative who said that formal training was un-necessary, because "to be boxed up with the insane means becoming a qualified nurse." 95 Some medical officers questioned whether it was necessary for "ordinary attendants" to know about scientific subjects, such as physiology, to help them care for patients. ${ }^{96}$ Others hoped that it would improve practice and recruitment and "eradicate faults of character". 97 "Faults of character" appeared to be a euphemism for unkind behaviour.

Anecdotal evidence suggested limited effects of the training. A former patient reported that he asked an attendant "Don't they give you talks on psychology?" and the attendant replied "What is that, something to eat?" 98 The attendant may have intended to be witty, but his comment suggested that his training lacked relevant content. Psychological skills might have been learnt on the wards, but it is less clear that there were enough knowledgeable senior ward staff with time and ability to demonstrate or encourage relevant therapeutic approaches. 
Staff interest in training varied, even though the certificate was key to promotion within the asylum system ${ }^{99}$ and to a salary bonus, usually $£ 2$ a year. ${ }^{100}$ At some asylums, such as Claybury almost one-third of ward staff held the certificate in 1914. ${ }^{101}$ Elsewhere, none possessed it. ${ }^{102}$ Pre-war, more attendants than nurses passed the exam, ${ }^{103}$ probably because attendants were more likely to consider their work as a life time job, compared to nurses who were less motivated to study because of the marriage bar. However, during the war, exam successes reversed: temporary attendants probably had less incentive than nurses on permanent contracts. ${ }^{104}$

The MPA considered that the work of asylum nurses and attendants was equivalent to that of general nurses and should be recognised as such. Consequently, it wanted the Royal British Nursing Association (RBNA) register to include asylum staff who held the MPA certificate. The RBNA rejected their request as it did not consider asylum staff trained nurses. The RNBA would have provided some trade union representation for the asylum ward staff, similar to the way the British Medical Association acted for doctors. ${ }^{105}$ Their rejection was associated with the establishment of a separate organisation the Asylum Worker's Association which became the National Asylum Worker's Union (NAWU) in 1910. ${ }^{106}$ It represented a disheartened and under-trained body of staff, and it focussed primarily on the well-being of the workforce rather than directly on the patients. In contrast to the NAWU, the College of Nursing (later, Royal College), established in 1916, had educational objectives. Its nurses were beginning to take a greater role in teaching their own profession. However, general nursing textbooks, similar to general textbooks for training doctors, hardly mentioned psychiatric symptoms, further reinforcing the compartmentalisation of mental and physical nursing. ${ }^{107}$ The College of Nursing and the NAWU indicated workers' needs: for general nurses, better education; for asylum workers, improved wages and employment conditions. Contrasting priorities indicated a self-confident general nursing profession, and an unsettled asylum workforce. In 1919 the establishment of the General Nursing Council, a regulatory body for the nursing profession in England and Wales, was heavily influenced by the RNBA leadership. It too did not recognise the MPA qualification, and in 1921 introduced its own. Soberingly, Kathleen Jones argued that "there were many mental nurses with neither the will nor the apparent ability to take either." 108 


\section{Medical Staff: Doctors and Dilemmas}

Medical students were taught a fairly standardised curriculum in "psychological medicine". Tracy Loughran analysed their education in psychological and psychiatric subjects in the context of her research on shell shock, arguing that medical students would have found it difficult to avoid acquiring some psychological knowledge in the course of their studies. ${ }^{109}$ However, clinical work was (and is) a practical art backed up by science, and art requires practice, not just knowledge. Medical students received practical training in medicine, surgery, pathology, obstetrics and gynaecology, but rarely in psychiatry. Without practice, lectures were unlikely to give them a secure grounding in the subject for their future careers. In addition, senior asylum doctors usually taught their courses, focussing on mental disorders encountered in daily asylum work, rather than those which most doctors would face in their general hospital or community practice. Standard textbooks were also often inadequate concerning psychiatry. Whereas they contained descriptions of physical symptoms (e.g. coughs) and indicated the characteristics and clinical significance of each type, they were likely only to define a psychiatric term (e.g. delusion) but neither explain its significance nor indicate its subtypes. ${ }^{10}$ Bernard Hollander, a psychiatrist, and Edward Younger, a physician with some psychiatric training, both questioned the relevance of the medical school curriculum. ${ }^{111}$ Younger worked at London's Finsbury Dispensary, providing out-patient services for working-class people. His textbook in 1914 contrasted with usual teaching, particularly by emphasising early stages of mental disorder, clinical assessment and legal matters relevant to the work of general practitioners. ${ }^{112}$

Pre-war, with little psychiatric training in medical schools, doctors working in asylums needed, but received, little in-service training to supplement their clinical experiences. A few spent time away from psychiatry, working in general hospitals, and sat the examination for Membership of the Royal College of Physicians. The MPA, as it had done for asylum nurses and attendants, set the ball rolling in asylum doctors' education. However, the MPA's "Certificate of Efficiency in Psychological Medicine" had neither a published curriculum nor official recognition. Several universities began to provide teaching for asylum doctors, ${ }^{113}$ giving them the opportunity to gain a Diploma in Psychological Medicine. That too was problematic. Although it went some way towards indicating a doctor's suitability to become a specialist, 
the diploma lacked the rigour and status of the examinations of the medical Royal Colleges. ${ }^{114}$ It thus did not increase the esteem of asylum doctors in the eyes of their physician and surgeon colleagues, for whom Royal College memberships and fellowships, and work in teaching hospitals, private clinics and charity-funded ("voluntary") general hospitals, comprised the pinnacle of professional clinical practice.

As with many other asylum staff, the doctors were dissatisfied with their terms and conditions of service. An anonymous asylum medical officer wrote to the British Medical Journal (BMJ) shortly before the war, drawing attention to medical staff vacancies: the recent pay rise was welcome but insufficient, and "Until some action is taken to improve existing conditions, the asylum medical officer will remain a professional pariah, whose life, like the policeman's, is 'not a happy one'." He ascribed some of the blame to medical superintendents who made little effort to improve matters. ${ }^{115}$ Around the same time, the $B M J$ also cited an MPA report that medical work in asylums, "leads to the stunting of ambition and a gradual loss of interest in scientific medicine, and it tends to produce a deteriorating effect upon those who remain long in the service." It also commented that the problem "demands the earnest attention of public authorities and all interested in the welfare of the insane" 116 ; asylum medical posts needed improving to attract and keep good staff. The MPA dedicated a half-day session to this at its annual meeting in July 1914, two weeks before war broke out. It recommended a greater variety of clinical responsibilities including investigating and treating new patients, better clinical supervision from senior medical officers, more training and study leave and some experience working in a general hospital. Medical officers should also be allowed to marry after 5 years' service and have house in the grounds; promotion should depend upon qualifications and personal qualities; and lay committees which lacked expertise to evaluate the clinical knowledge or skills of the applicant were unsuitable for appointing medical staff. ${ }^{117}$ Implementing the changes would need collaboration between various bodies such as local authorities to fund locums to cover study leave; general hospitals to facilitate placements; and VCs to build more staff accommodation.

With numerous vacancies for asylum doctors, some took jobs in asylums when they were unable to find work elsewhere. This may have given Herbert Ellis, a magistrate and VC member, the impression that assistant medical officers lacked ability, interest and enthusiasm, contrasting with often impressive medical superintendents who 
had high standards and knew their patients well. ${ }^{118}$ Former patient, Charles McCarthy, a retired civil servant, was less charitable, describing one asylum doctor as "after the type of a low English navvy", and the medical superintendent as "an English snob with an imitation University accent."119 Standards of asylum clinical work could be dismal. Medical assessments might not be entered in the patients' notes and a batch of mandatory clinical reviews might be added just before a Board inspection. ${ }^{120}$ The Board nudged: "instead of making so many on one day (sometimes we observe over 100)" it would be better if "an endeavour were made to distribute them over the year, so that only a few fall due each day." 121 Neglectful, rushed and superficial clinical assessments may have been due to doctors' laziness or lack of skills or interest, but could also have been an effect of the asylum system, its values and economic restrictions, with unsuitable recruitment processes, medical understaffing and excessive workloads. As with the relationship between VCs and the asylum workforce generally, that between a medical superintendent and his junior staff could be equally fraught. The medical superintendent at Prestwich Asylum showed little respect for his junior doctors. He described them as "the flotsam and jetsam and scum of the earth", with the second part of the sentence deleted in the transcript of the Cobb Inquiry. ${ }^{122}$ The comments from the superintendent about his medical staff seem excessive, even if some of them were second-rate.

Many doctors endeavoured to practice high standards of medicine, but things could still go wrong. In those circumstances, doctors appear to have been punished more leniently than their non-medical colleagues, probably because their professional status unfairly accorded them some immunity. Five women patients died one night in 1914 at the Bethlem Hospital, all by poisoning from amylene hydrate, a sedative. A seriously depleted staff at the beginning of the war resulted in the on-call doctor, Henry Jones, being called on to dispense medications from stock bottles. He poured amylene from the bottle containing the concentrated, rather than the diluted, solution, giving each woman eight times the usual dose. The Times reported the coroner's jury's verdicts of "death by misadventure". ${ }^{123}$ The coroner recommended that medical officers should not have to undertake dispensing and a "qualified paid dispenser" should be employed. The Bethlem adopted this proposal and arranged for concentrated and diluted medications to be stored separately. ${ }^{124}$ There is no evidence that Jones was punished for his error. Indeed, his career progressed, despite the disaster. Jones became medical superintendent at 
Fulbourn Hospital, Cambridge, where his eccentricities and personal style received greater acclaim than his clinical leadership. ${ }^{125}$

In summary, poor standards of medical practice, scarcity of doctors willing to enter asylum work, plus many medical officers enlisting early in the war, were likely to prejudice patient care. ${ }^{126}$

\section{Serving The Colours}

Medical officers, alongside attendants and some staff who fulfilled unique roles in the asylum, enlisted or transferred to war work. When Hanwell's tin smith went to work in a munitions factory, colleagues at other LCC asylums covered for him. ${ }^{127}$ From Colney Hatch, the "last permanent hand in the tailor's shop" and the upholsterer, whose jobs included furniture renovation and repairing blinds and mattresses, ${ }^{128}$ left to join the army in the same week. ${ }^{129}$ That was especially tricky when repair rather than replacement had become the norm. The Board complied with instructions, in line with national propaganda and public opinion, to release the maximum numbers of staff to achieve the overriding goal of bringing hostilities to a satisfactory close and return to a "proper standard" as soon as possible thereafter. ${ }^{130}$ With many men serving the Colours, women, and men over military recruitment age, took over their duties. $^{131}$ Much leave was curtailed at the beginning of the war, with promises that annual leave would accrue and that overtime would be paid. ${ }^{132}$

Nationally, over one million volunteers were recruited into military service by the end of 1914, but more were needed. The LCC encouraged asylum staff to enlist. ${ }^{133}$ By March 1915, over 500 men, about a quarter of the total male staff across all the LCC asylums, were serving with the military forces. At the end of 1915, the LCC resolved that any asylum employee who wanted to join the army under the scheme established by Lord Derby, Director General of Recruiting, should be permitted to do so. If he could not be spared immediately, his name would be transferred to the army reserve list, to provide time to find a substitute. ${ }^{134}$ The LCC based its strategy on the premise that difficulties in the asylums could be overcome with careful financial management and a "helpful fluidity of staff". The latter implied that staff would move from asylum to asylum as required, although the LCC did not state how it might find enough adequately trained staff for this. The Board encouraged the LCC 
scheme with a little flattery, that "the London Asylums, the pioneers in the Asylum world" would set an example to others. ${ }^{135}$

In March 1916 the Military Service Act introduced conscription except for those in essential occupations. Very few asylum jobs fell into this category. Of 6500 attendants in the asylum service in England and Wales before the war, a skeleton of 1500 were deemed indispensable. ${ }^{136}$ Doctors were in demand to serve the nation, and almost half those working in asylums undertook military service. Many of those who replaced them had less asylum experience, were physically unfit, or had retired from clinical practice. ${ }^{137}$ (Lomax was an older, retired doctor, working in this capacity at Prestwich Asylum. ${ }^{138}$ ) By mid-1916, the ratio of doctors to patients in the asylums deteriorated from an average of 1 to 250 , to 1 to $390 .{ }^{139}$ Medical staffing was so inadequate that some asylum doctors spent their leave from the army working in the asylum which had agreed to their military service and to which they expected to return. More clinical work fell on the shoulders of the medical superintendents. One asylum reported a "large amount of illness in the institution" which needed a "reliable permanent assistant who could relive him [the medical superintendent] of some of the very heavy responsibilities which he is now called upon to bear." 140

The LCC offered financial support to military recruits, topping up military pay where necessary to its usual asylum level, including emoluments and increments. ${ }^{141}$ The principle was that those undertaking military service should not be financially disadvantaged compared to those remaining behind. To ensure this, asylums also caped the salaries of existing staff, such as when "acting up" into more senior roles. However, as the war lengthened some asylums had to ignore the salary caps to allay staff unrest and to stem the tide of pay-related resignations. ${ }^{142}$ Elsewhere, VCs deferred payment of additional wages, promising that the matter would be considered at some later date. ${ }^{143}$ VCs were also prohibited from appointing new permanent staff. This was well intentioned, aiming to ensure that eligible staff on military service would have equal opportunity to apply for permanent posts on their return, but the consequences of temporary appointments, or rapid promotion into acting roles, risked sub-standard leadership and destabilising asylum function. ${ }^{144}$

In 1916, the MPA approached the Board, concerned about falling staff levels. It feared the consequences of lower standards of care, such as "extensive resort to seclusion and mechanical and chemical restraint which prevailed in the days when attendants were few and inefficient." 
It asked the Board to help secure exemptions from military service "To save the already dangerously depleted asylums from the almost complete denudation of a skilled and physically fit staff of male attendants." 145 The Board appeared keener to follow the national priorities rather than more patient focussed advocacy of the MPA. In 1917, on behalf of the War Office, the Board appealed for more medical men from the asylums. ${ }^{146}$ The LCC, which until then had encouraged military recruitment, uncompromising refused. ${ }^{147}$ The Board reiterated the recruitment request early in 1918 , continuing to comply with the War Office, "that every fit man of military age should be available for military service". ${ }^{148}$ The Board rejected pleas from the LCC and MPA about falling standards of care.

At the end of the war, asylums were desperate for their staff to return, but there was no plan to demob asylum employees any earlier than anyone else. ${ }^{149}$ By April 1919, most LCC asylum staff had returned to their peace-time work. However, despite concern by the asylum authorities about medical staffing levels, 26 of 28 medical officers from LCC asylums remained absent from their civilian posts, still not demobbed. ${ }^{150}$ The asylums were not alone in their dissatisfaction about the slow rate of demobilisation and the inequities of its application. Demobilisation aimed to be in accordance with the strategic importance of an individual's civilian occupation: a coal miner, for example, was high priority. ${ }^{151}$ Regarding asylum doctors, there seemed to be little official awareness of their civilian roles. This fitted with national understanding and priorities concerning civilian mental and physical health. ${ }^{152}$ However, the return of doctors was probably also delayed because physical and mental war wounds did not disappear with the signing of the Armistice. Thus, in the established hierarchies of military needs and civilian mental health needs, it is hardly surprising that asylum doctors experienced late demobilisation. Nationally, one million men were still in uniform in September 1919 and 125,000 awaited return to civilian life in early 1920. The delays caused much distress, ${ }^{153}$ not solely to asylums.

Through the war, the Board and VCs regularly reported on asylum personnel serving the Colours. News of their deaths, injuries, promotions and gallantry ${ }^{154}$ may have motivated remaining staff to work harder, in line with propaganda and despite the challenges they faced. From the LCC asylums, 952 men (about half of the male workforce) served in the forces. Ninety-seven were killed, dead or missing, 160 wounded, and 31 gained military distinctions including three with the Military Cross. ${ }^{155}$ 
Others suffered physical illnesses and shell shock. ${ }^{156}$ Some, such as attendant Thomas Wells received support when back at his asylum. Employed at Claybury since 1907, he served in the army for two years. On his return, he had difficulty undertaking some tasks. When he refused to bathe a patient, his seniors reported him to the medical superintendent. The superintendent recognised that he was suffering from shell shock and negotiated alternative, less distressing work for him on the farm. ${ }^{157}$ Not all traumatised returning staff received sympathy. Attendant Franklin Graimes from Hanwell enlisted in 1914 age 26, and served for three years, and was invalided out of the army suffering from shell shock. ${ }^{158}$ Back at Hanwell, he was too unwell to resume his duties. The VC showed little tolerance of his symptoms or willingness to modify his duties. Instead they encouraged him to resign, which he did. ${ }^{159}$ Lack of sympathy towards people with mental disorders existed, including within the mental health service leadership, and even towards former soldiers who public mandate demanded were to be treated with respect.

The Board unswervingly followed the patriotic party line, despite intermittent opposition from the MPA and the LCC who were concerned about the risks to asylum patients. It was rare for the Board to advocate for patients in the face of competing national pressures, despite the image they sought to present of themselves as working in their best interests. ${ }^{160}$ Rather, they seemed to prioritise their organisational and personal reputations: Marriott Cooke, chairman of the Board during the war, was knighted for his war services, not for his commitment to the asylums and their staff and patients. ${ }^{161}$

\section{TOWARDS THE END OF THE WAR}

Despite simmering staff discontent, the NAWU kept a fairly low profile until 1918. ${ }^{162}$ By then, some ward staff were working 100 hours a week and there was a nadir of morale. At the same time, trade unions were becoming more influential across many occupational groups ${ }^{163}$ and strikes by public service workers, including the police, took place before the war ended. The NAWU placed before the Lancashire Asylums Board $(\mathrm{LAB})$ a list of nine requests, varying from permission to post their union notices in the staff mess rooms to improving pay and conditions for attendants and nurses. The LAB rejected them all. On 4 September 1918, 200 asylum staff came out on strike at Prestwich. The following day 449 attendants stopped work at Whittingham. At Winwick there was a go 
slow and a suggestion that the strike would spread to asylums outside Lancashire. The LAB agreed to submit the items under dispute to arbitration by the Ministry of Labour (established in 1916) and promised that no employee on strike would be penalized. In the light of having organised this protest, despite the claims eventually being rejected at arbitration, the NAWU's prestige rose and its membership increased. Capitalizing on their success, at the end of September 1918 the NAWU adopted a national programme for the future. It included plans to implement a 48-hour week; a minimum weekly wage of $£ 2$ for the most junior nurses; equal pay for equal work for men and women; registration for the profession of mental nursing; and universal recognition by the asylum authorities of the union as a negotiating body. ${ }^{164}$ The Board's fifth annual report for 1918 acknowledged the NAWU for the first time. The Board situated asylum changes in the context of a general "movement of the working classes" to secure better pay and employment conditions. It stated that it was already aware of the need to do this, but counterbalanced its argument by repeating the problem of economic hurdles concerning "the burden imposed on the nation by the mass of mental defect and disorder". ${ }^{165}$ The Board, having done little to advocate for patients or staff over the previous 4 years, said that it knew what to do and paid short shrift to the NAWU.

\section{CONCLUSIONS}

Strict rules and attitudes of asylum leaders towards their staff echoed military discipline as a means of controlling lower ranks. This style may have been appropriate to soldiers on the front line in battle, but it was unsuited to the asylum front line where the aim was to improve the health and wellbeing of patients through "care and treatment". The "systematic petty tyranny" detected in Scottish asylums was also present in their English counterparts, a culture of excessively harsh and rigid attitudes and behaviours which passed through the asylums as far as the patients whose treatment often fell short of ideal. Insufficiently trained lower levels of staff were likely to perpetuate the tyranny, modelling their own behaviours and attitudes on their experiences of those in authority who demonstrated how seniors behaved towards subordinates.

Organisational rigidity imposed by the Lunacy Act and the leadership discouraged changes in asylum practices and inhibited creativity to deal proactively with new eventualities. Lay management committees running 
the asylums, despite working closely with senior asylum officers, particularly the medical superintendent, may have contributed to this. Their lack of expertise may have made them uncertain in their decision making and more dependent on rules and regulations. Concerning staff, the management showed little interest in their wellbeing, although some helpful flexibility appeared regarding rules about marriage and about giving staff options to live beyond the perimeter wall, although that commenced pre-war. The motivation for these changes may have been the limited amount of married accommodation available, the cost and inconvenience of building more, and fear of further workforce depletion, rather than staff wellbeing as such. Albeit small, the changes were in line with staff needs, and did not precipitate disaster.

Goffman wrote about a two-way staff-inmate split in institutions:

Each group tends to conceive of the other in terms of narrow hostile stereotypes, staff often seeing inmates as bitter, secretive, and untrustworthy, while inmates often see staff as condescending, high handed and mean. Staff tends to feel superior and righteous; inmates tend, in some way at least, to feel inferior, weak, blameworthy and guilty. ${ }^{166}$

The wartime asylums appeared to have a three-way split: seniors including the VC; subordinate staff; and patients. The relationship between seniors and subordinate staff and that between subordinate staff and patients both fitted with Goffman's staff-inmate pattern. Neither facilitated a happy working relationship.

Although some staff worked long-term in the asylums and appeared settled within an institutional regime, many others were discontent, morale was low, and staff had a high turnover both before and during the war. The establishment of the NAWU indicated staff concerns-pay, hours, accommodation and other conditions of employment-in contrast to the education and professionalisation priorities in general nursing. By the end of the war, with increased staff unrest and higher union membership, the NAWU was a greater force for change. A similar shift occurred in other employment sectors. ${ }^{167}$ The NAWU appeared to listen to staff feedback about their needs in contrast to the asylum leadership which was out of touch with its workforce.

Official status or rank carried significant weight in the asylums, affecting who listened to whom, and to whom punishment-or sometimes praise-was directed. Praise and punishment were doled out 
inequitably, such as punishing doctors more leniently than ward staff for breaching rules or making errors. Responses to staff deemed unsuitable varied in other ways, such as how to support former soldiers who returned to their asylum employment while suffering from shell shock, or what to do when nurses were unhappy about working on male wards. Although we do not have details, such as about individual staff members' past work record, decisions on their employment status appear unfair, and sometimes lacking compassion.

The asylum leadership prioritised conforming to rules and expected everyone to do likewise. A conformist system could contribute to a sense of place and security for the leadership and belief that they behaved in the correct manner. This would reinforce existing practices, but would not encourage lateral thinking about alternatives, or querying whether some of the asylum's staffing difficulties were due to the system which they led. It is likely that the asylum leadership contributed to a dysfunctional system in which lower ranks of staff were undervalued and unappreciated.

\section{Notes}

1. Select Committee on the Asylum Officers (Employment, Pensions and Superannuation) Bill, Report and Special Report Together with the Proceedings of the Committee (London: HMSO, 1911), iv.

2. Dr. Pasmore in discussion about "Asylum Administration as Affected by Present Events," Journal of Mental Science (JMS) 65 (1919): 124-29, 127.

3. First Annual Report of the Board of Control, for the Year 1914 (London: HMSO, 1916) (BoC AR 1914), Part 2, 154; Anon. The LCC Hospitals: A Retrospect (London: LCC, 1949), 108; LCC LCC/MIN/00754 Minutes of miscellaneous sub-committees 1915-1919: Summary of staff numbers required for a 48-hour week, LMA.

4. LCC LCC/MIN/00759 Presented papers of sub-committee 19091923: tradesmen in asylums 1910, LMA.

5. Colney Hatch LCC/MIN/01005 Meeting, 19 May 1916, 162; H12/CH/C/04/003 Male attendants' wages book 1915-1916, LMA.

6. Asylums Officers (Employment, Pensions, and Superannuation) Bill. Hansard HC Deb, 21 May 1914, vol. 62, c2132.

7. E. Marriott Cooke and C. Hubert Bond, History of the Asylum War Hospitals in England and Wales (London: HMSO, 1920), 2.

8. "Asylum Worker's Association, Extract from Sir James CrichtonBrowne's Address," JMS 61 (1915): 479-80. 
9. Colney Hatch LCC/MIN/01006 Meeting, 7 September 1917, 234-36 LMA.

10. Erving Goffman, Asylums: Essays on the Social Situation of Mental Patients and Other Inmates (1961; Harmondsworth: Penguin, 1980).

11. Colney Hatch LCC/MIN/01003 Meeting, 31 July 1914, 57 LMA.

12. Hanwell H11/HLL/C/06/006 Male attendants' fine book 19141935, 18 June 1917 LMA.

13. Colney Hatch LCC/MIN/01006 Meeting, 1 December 1916, 37 LMA; BoC AR 1914, Part 2, Salop Asylum 8 July 1914, 298; Peter Nolan, A History of Mental Nursing (London: Chapman and Hall, 1993), 57, 74 .

14. Hanwell H11/HLL/C/06/006 Male attendants' fine book 19141935, 22 May 1916 LMA.

15. LCC LCC/MIN/00579 Meeting, 26 May 1914, 463 LMA; Colney Hatch LCC/MIN/01003 Meeting, 18 December 1914, 215-16 LMA.

16. Claybury LCC/MIN/00948 Meeting, 8 November 1917, 244 LMA.

17. Hanwell H11/HLL/C/06/006 Male attendants' fine book 19141935; 18 June 1917; 16 February 1914; 15 November 1920; 21 July 1913 LMA.

18. Bedford Pierce, "Some Present Day Problems Connected with the Administration of Asylums," JMS 65 (1919): 198-201, 198.

19. Colney Hatch LCC/MIN/01001 Meeting, 25 April 1913, 42 LMA.

20. Nolan, History, 74.

21. Colney Hatch LCC/MIN/01007 Meeting, 17 May 1918, 75 LMA; sometimes 10.30 p.m. in summer.

22. Napsbury H50/A/01/024 Meeting, 6 August 1915, 117 LMA.

23. Colney Hatch LCC/MIN/01002 Meeting, 27 March 1914, 183 LMA.

24. England Census 1891, 1901, 1911, https://www.ancestry.co.uk/sea rch/categories/ukicen/.

25. Colney Hatch LCC/MIN/01005 Meeting, 7 April 1916, 122 LMA.

26. Colney Hatch LCC/MIN/01002 Meeting, 13 February 1914, 125 LMA.

27. LCC LCC/MIN/00583 Meeting, 24 July 1917, 35 LMA.

28. LCC LCC/MIN/00582 Meeting, 30 January 1917, 408-9 LMA.

29. Colney Hatch LCC/MIN/01006 Meeting, 17 November 1916, 57 LMA.

30. LCC LCC/MIN/00583 Meeting, 26 March 1918, 429 LMA.

31. Colney Hatch LCC/MIN/01005 Meeting, 19 May 1916, 165 LMA.

32. LCC LCC/MIN/00580 Meeting, 27 April 1915, 392 LMA.

33. BoC AR 1914, Part 2, Isle of Wight Asylum 21 April 1914, 319.

34. Montagu Lomax, The Experiences of an Asylum Doctor (London: Allen and Unwin, 1921), 117-18. 
35. Colney Hatch LCC/MIN/01002 Meeting, 13 March 1914, 163-64 LMA.

36. Hanwell LCC/MIN/01093 Meeting, 22 December 1913, 27 LMA.

37. Hanwell LCC/MIN/01095 Meeting, 7 June 1915, 66 LMA.

38. Select Committee on the Asylum Officers Bill, Report, iv; Neil Brimblecombe, "Asylum Nursing as a Career in the United Kingdom, 1890-1910," Journal of Advanced Nursing 55 (2006): 770-77, 770.

39. Nolan, History, 75; BoC AR 1914, Part 2, Cumberland and Westmorland Asylum 23 July 1914, 212; Oxford Asylum 4 August 1914, 296.

40. BoC AR 1914, Part 2, Winwick Asylum 24 February 1914, 257.

41. Select Committee on the Asylum Officers Bill, Report, iii-v, vii.

42. BoC AR 1914, Part 2, Winwick Asylum 24 February 1914, 257.

43. LCC LCC/MIN/00579 Meetings: 16 December 1913, 94; 27 January 1914, 135 LMA; Department of Employment and Productivity, British Labour Statistics: Historical Abstract 1886-1968 (London: HMSO, 1971), 28, 30, 39.

44. Select Committee on the Asylum Officers Bill, Report, iv.

45. Nolan, History, 75, 77.

46. Select Committee on the Asylum Officers Bill, Report, v.

47. BoC AR 1914, Part 2, Oxford Asylum 4 August 1914, 295.

48. Colney Hatch LCC/MIN/01004 Meeting, 2 July 1915, 155 LMA.

49. Hanwell LCC/MIN/01097 Meeting, 24 September 1917, 181-83 LMA.

50. Committee on the Administration of Public Mental Hospitals (Chairman: Sir Cyril Cobb) (Cobb Inquiry), 15 March 1922 AM Donaldson Q:576, MH 58/219 TNA.

51. Colney Hatch H12/CH/C/03/004 Officers' salaries book 1910-1917, LMA.

52. Lunacy Act 1890 section 276 (1) (b) (c).

53. Claybury LCC/MIN/00946 Meeting, 24 March 1915, 81 and between pp. 71-72 LMA.

54. Colney Hatch $\mathrm{H} 12 / \mathrm{CH} / \mathrm{C} / 04 / 004$ Male attendants' wages book 1917-1918 LMA.

55. Colney Hatch $\mathrm{H} 12 / \mathrm{CH} / \mathrm{C} / 03 / 004$ Officers' salaries book 1910-1917 LMA; Hanwell LCC/MIN/01096 Meeting, 5 June 1916, 83 LMA.

56. Department of Employment and Productivity, British Labour Statistics, 38-39; Brimblecombe, "Asylum Nursing": 770.

57. Leonard Smith, "Behind Closed Doors: Lunatic Asylum Keepers, 18001860," Social History of Medicine 1 (1988): 301-27, 327.

58. Ministry of Health, Report of the Committee on Administration of Public Mental Hospitals Cmd. 1730 (Chairman: Sir Cyril Cobb) (London: HMSO, 1922); Lomax, Experiences, 51. 
59. BoC, "Memorandum for the Minister of Health on Mr. Montagu Lomax's Book The Experiences of an Asylum Doctor," 21 September 1921, MH 52/222 TNA.

60. Colney Hatch LCC/MIN/01002 Meeting, 30 January 1914, 113 LMA.

61. BoC AR 1914, Part 2, Dorset Asylum 12 May 1914, 222.

62. Cobb Inquiry, 15 March 1922 Mr. Cox Q:401, MH 58/219 TNA.

63. Cobb Inquiry, 30 March 1922 Edward Mason Q:2112, MH 58/220 TNA.

64. Lomax, Experiences, 84; Nolan, History, 83.

65. Charles Mercier, The Attendant's Companion: A Manual of the Duties of Attendants in Lunatic Asylums (London: J and A Churchill, 1898), 2.

66. Lunacy Act 1890, section 53.

67. Napsbury H50/A/01/026 Meeting, 22 July 1916, 37 LMA.

68. George Robertson, "The Employment of Female Nurses in the Male Wards of Mental Hospitals in Scotland," JMS 62 (1916): 351-62, 361.

69. Robertson, "Employment of Female Nurses": 362.

70. Nolan, History, 70.

71. Tom Walmsley, "Psychiatry in Scotland," 294-305, in 150 Years of British Psychiatry 1841-1991, ed. German Berrios and Hugh Freeman (London: Gaskell, 1991), 303.

72. Hanwell H11/HLL/A/06/05 Draft annual report 1917 LMA.

73. BoC AR 1914, Part 2, Northumberland Asylum 4 May 1914, 292.

74. Claybury LCC/MIN/00946 Meeting, 14 October 1915, 241 LMA; BoC AR 1914, Part 2, Severalls Asylum 27 October 1914, 227.

75. Claybury LCC/MIN/00946 Meeting, 14 October 1915, 241 LMA; Hanwell LCC/MIN/01097 Meeting, 2 July 1917, 118-19 LMA.

76. Brimblecombe, “Asylum Nursing": 770.

77. Hanwell $\mathrm{H11} / \mathrm{HLL} / \mathrm{C} / 03 / 001$ Letters of recommendation and testimonials of female asylum staff 1903-1923, using sample from 1910 to 1919 LMA.

78. LCC LCC/MIN/00580 Meeting, 29 June 1915, 638-39; Colney Hatch LCC/MIN/01004 Meeting, 2 July 1915, 152: LCC/MIN/01005 Meeting, 22 September 1916, 270 LMA.

79. LCC LCC/MIN/00582 Meeting, 30 January 1917, 402 LMA.

80. Claybury LCC/MIN/00949 Meeting, 5 December 1918, 250 LMA; Napsbury H50/A/01/026 Meeting, 6 October 1916, 115 LMA; Louise Hide, Gender and Class in English Asylums, 1890-1914 (London: Palgrave Macmillan, 2014), 45-46.

81. BoC AR 1914, Part 1, vi; LCC LCC/MIN/00581 Meeting, 14 March 1916, 424; LCC/MIN/00584 Meeting, 8 October 1918, 2-4 LMA.

82. Colney Hatch LCC/MIN/01004 Meeting, 27 August 1915, 197 LMA.

83. Claybury LCC/MIN/00948 Meeting, 15 March 1917, 57 LMA. 
84. LCC: LCC/MIN/00581 Meeting, 30 November 1915, 178; LCC/MIN/00584 Meeting, 8 October 1918, 3 LMA.

85. LCC LCC/MIN/00581 Meeting, 18 April 1916, 484 LMA.

86. Claybury LCC/MIN/00949 Meeting, 20 June 1918, 130 LMA.

87. Nolan, History, 62.

88. Vicky Long, Destigmatising Mental Illness? Professional Politics and Public Education in Britain, 1870-1970 (Manchester, UK: Manchester University Press, 2014), 67.

89. Thomas Bewley, Madness to Mental Illness: A History of the Royal College of Psychiatrists (London: RCPsych Publications, 2008), 115.

90. Age 14 after Education Act 1918.

91. Nolan, History, 62.

92. MPA, Handbook for the Instruction of Attendants on the Insane (London: Baillière, Tindall and Cox, 1885); MPA, Handbook for Attendants on the Insane (6th Edition) (London: Baillière, Tindall and Cox, 1911); Bewley, Madness to Mental Illness, 114.

93. Napsbury H50/A/01/024 Meeting, 16 October 1915, 220 LMA.

94. Colney Hatch LCC/MIN/01007 Meeting, 22 February 1918, 39 LMA.

95. Dr. Turner in discussion about "Asylum Administration as Affected by Present Events," JMS 65 (1919): 124-29, 129.

96. Bewley, Madness to Mental Illness, 114.

97. Nolan, History, 82.

98. Cobb Inquiry, 30 March 1922 Edward Mason Q:2138, MH 58/220 TNA.

99. Colney Hatch LCC/MIN/01007 Meeting, 22 February 1918, 39 LMA.

100. LCC LCC/MIN/00579 Meeting, 4 November 1913, 19 LMA.

101. BoC AR 1914, Part 2, 1914 Claybury Asylum 27 June 1914, 270.

102. BoC AR 1914, Part 2, Berks Asylum 6 May 1914, 198.

103. BoC AR 1914, Part 2, Brecon and Radnor Asylum 6 May 1914, 199.

104. Claybury LCC/MIN/00946 Meeting, 22 July 1915, 190 LMA; Colney Hatch LCC/MIN/01005 Meeting, 2 June 1916, 192 LMA.

105. Royal British Nursing Association, https://www.rbna.org.uk/.

106. Francis Adams, "From Association to Union: Professional Organization of Asylum Attendants, 1869-1919," British Journal of Sociology 20 (1969): 11-26, 12.

107. Georgiana Sanders, Modern Methods in Nursing (Philadelphia and London: WB Saunders, 1912), 703-9.

108. Kathleen Jones, Mental Health and Social Policy, 1845-1959 (London: Routledge and Kegan Paul, 1960), 102.

109. Tracy Loughran, Shell Shock and Medical Culture in First World War Britain (Cambridge: Cambridge University Press, 2017), 23, 33. 
110. G Elliott Smith and Tom Pear, Shell Shock and Its Lessons (Manchester: University Press, 1917), 111, 118-19.

111. Edward Younger, Insanity in Everyday Practice (London: Baillière, Tindall and Cox, 1914), 1; Bernard Hollander, The First Signs of Insanity: Their Prevention and Treatment (London: Stanley Paul and Co, 1912), 21.

112. Younger, Insanity, vii, 16-22.

113. Anon. "Facilities Provided for the Teaching of Psychiatry," JMS 59 (1913): 159-60.

114. Hugh Freeman, "Psychiatry in Britain c. 1900," History of Psychiatry 21 (2010): 312-24, 320.

115. An AMO, "Assistant Medical Officers in Asylums," BMJ 9 August 1913, 349.

116. Anon. "The Asylum Service," BMJ 29 November 1913, 1447-1448, 1448 .

117. Anon. "The Medico-Psychological Association of Great Britain and Ireland," JMS 60 (1914): 644-95, 669-73.

118. Cobb Inquiry, 16 March 1922 Herbert Ellis Q:862, 872, MH 58/219 TNA.

119. Cobb Inquiry, 16 March 1922 Charles McCarthy Q:819, 823, MH $58 / 219$ TNA.

120. BoC AR 1914, Part 2, Kesteven Asylum 27 January 1914, 263.

121. BoC AR 1914, Part 2, Hants Asylum 6 November 1914, 234.

122. Cobb Inquiry, 24 February 1922 Dr. Perceval Q:410, MH 58/219 TNA.

123. BoC W/FM, 11 November 1914, $236 \mathrm{MH} \mathrm{50/43} \mathrm{TNA;} \mathrm{Anon.} \mathrm{"News}$ in Brief," Times, 13 November 1914.

124. BoC AR 1914, Part 1, 37.

125. David Clark, The Story of a Mental Hospital: Fulbourn 1858-1983 (London: Process Press, 1996), 54, 192.

126. BoC AR 1914, Part 1, 15-16.

127. Hanwell LCC/MIN/01095 Meeting, 7 June 1915, 96 LMA.

128. Cobb Inquiry, 30 March 1922 Dr. Ogilvy Q:1806-7, MH 58/220 TNA.

129. Colney Hatch LCC/MIN/01006 Meeting, 17 November 1916, 12 LMA.

130. Third Annual Report of the Board of Control, for the Year 1916 (London: HMSO, 1917) (BoC AR 1916), 10; BoC to MPA, untitled letter 17 May 1916, JMS 62 (1916): 637-38.

131. Initially 19-30 years, then 18-41. From April 1918, 18-51.

132. LCC LCC/MIN/00579 Meeting, 29 September 1914, 649 LMA.

133. LCC LCC/MIN/00580 Meeting, 22 December 1914, 131 LMA. 
134. LCC LCC/MIN/00581 Meeting, 9 November 1915, 111, 128 LMA; BoC AR 1916, 9-10.

135. LCC LCC/MIN/00581 Meeting, 30 May 1916, 604-5 LMA.

136. BoC AR 1916, 9-10.

137. Kathleen Jones, Asylums and After (London: Athlone Press, 1993), 124.

138. Anon. "Montagu Lomax MRCS Eng, LRCP Edin," Lancet 25 March 1933, 668.

139. Anon. "Asylum accommodation," JMS 62 (1916): 827-28.

140. Colney Hatch LCC/MIN/01007 Meeting, 11 January 1918, 5-6 LMA.

141. LCC LCC/MIN/00579 Meeting, 29 September 1914, 646 LMA.

142. Colney Hatch LCC/MIN/01007 Meeting, 11 January 1918, 4 LMA; LCC/MIN/01005 Meeting, 2 June 1916, 173; LCC LCC/MIN/00584 Meeting, 8 October 1918, 2-4 LMA; Hanwell LCC/MIN/01094 Meeting, 15 March 1915, 284-85 LMA.

143. LCC LCC/MIN/00581 Meeting, 26 October 1915, 56 LMA.

144. Claybury LCC/MIN/00948 Meeting, 5 July 1917, 134-35 LMA.

145. MPA to BoC, untitled letter, 17 May 1916, JMS 62 (1916): 636-37.

146. BoC W/FM, 21 March 1917, $97 \mathrm{MH} 50 / 45$ TNA.

147. LCC LCC/MIN/00582 Meeting, 27 March 1917, 568-69; 3 April 1917, 589 LMA.

148. LCC LCC/MIN/00583 Meeting, 29 January 1918, 319 LMA.

149. BoC, circular to superintendents, 23 December 1918, MH 51/239 TNA.

150. LCC LCC/MIN/00584 Meeting, I April 1919, 432 LMA.

151. Richard van Emden and Steve Humphries, All Quiet on the Home Front: An Oral History of Life in Britain During the First World War (London: Headline, 2003), 297.

152. Pat Thane, Divided Kingdom: A History of Britain, 1900 to the Present (Cambridge: Cambridge University Press, 2018), 56-57; JM Winter, "Military Fitness and Civilian Health in Britain During the First World War," Journal of Contemporary History 15 (1980): 211-44, 211.

153. Van Emden and Humphries, All Quiet, 300.

154. Hanwell LCC/MIN/01097 Meeting, 17 December 1917, 251 LMA.

155. LCC LCC/MIN/00584 Meeting, I April 1919, 432 LMA.

156. Colney Hatch LCC/MIN/01006 Meeting, 30 November 1917, 301; Claybury LCC/MIN/00946 Meeting, 23 December 1915, 318 LMA.

157. Claybury LCC/MIN/00948 Meeting, 19 July 1917, 176-77 LMA.

158. British Army WWl Pension Records 1914-1920, https://www.anc estry.co.uk/search/collections/britisharmy/; UK, Silver War Badge Records 1914-1920, https://www.ancestry.co.uk/search/collections/ silverwarbadgemedals/.

159. Hanwell LCC/MIN/01097 Meetings: 22 October 1917, 19; 17 December 1917, 252-54 LMA. 
160. Robert Armstrong-Jones, "The Eighth Annual Report of the Board of Control for the Year 1921," Eugenics Review 15 (1923): 426-32, 432.

161. HB, "Sir Marriott Cooke KBE MB," BMJ 31 October 1931, 829-30.

162. Nolan, History, 79.

163. Trades Union Congress, A Short History of British Trade Unionism: A TUC Study Pamphlet (London: Trades Union Congress, 1947), 21.

164. Adams, "From Association to Union": 19-20.

165. Fifth Annual Report of the Board of Control, for the Year 1918 (London: HMSO, 1919), 4.

166. Goffman, Asylums, 18.

167. Trades Union Congress, A Short History, 21.

Open Access This chapter is licensed under the terms of the Creative Commons Attribution 4.0 International License (http://creativecommons.org/licenses/ by $/ 4.0 /)$, which permits use, sharing, adaptation, distribution and reproduction in any medium or format, as long as you give appropriate credit to the original author(s) and the source, provide a link to the Creative Commons license and indicate if changes were made.

The images or other third party material in this chapter are included in the chapter's Creative Commons license, unless indicated otherwise in a credit line to the material. If material is not included in the chapter's Creative Commons license and your intended use is not permitted by statutory regulation or exceeds the permitted use, you will need to obtain permission directly from the copyright holder.

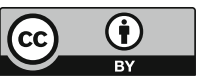

